\title{
Propriedades, eficácia e segurança do uso do ácido hialurônico em harmonização orofacial
}

\author{
Properties, efficacy and safety of hyaluronic acid use in orofacial harmonization \\ Propiedades, eficacia y seguridad del uso del ácido hialurónico en la armonización orofacial
}

Recebido: 29/09/2021 | Revisado: 10/10/2021 | Aceito: 11/10/2021 | Publicado: 12/10/2021

\author{
Matheus Rangel Alves Ribeiro \\ ORCID: https://orcid.org/0000-0002-5634-1459 \\ Centro Universitário de Patos de Minas, Brasil \\ E-mail: matheusrar@unipam.edu.br \\ Antônio Afonso Sommer \\ ORCID: https://orcid.org/0000-0003-0465-0222 \\ Centro Universitário de Patos de Minas, Brasil \\ E-mail: antonioas@unipam.edu.br \\ Rodrigo Soares de Andrade \\ ORCID: https://orcid.org/0000-0001-6114-0929 \\ Centro Universitário de Patos de Minas, Brasil \\ E-mail: rodrigosa@unipam.edu.br \\ Thiago de Amorim Carvalho \\ ORCID: https://orcid.org/0000-0003-1153-0931 \\ Centro Universitário de Patos de Minas, Brasil \\ E-mail: thiagocarvalho@unipam.edu.br \\ Maria Teresa Borges Araújo \\ ORCID: https://orcid.org/0000-0002-6866-1345 \\ Centro Universitário de Patos de Minas, Brasil \\ E-mail: mariateresa@unipam.edu.br \\ Patrícia Cristine de Oliveira Afonso Pereira \\ ORCID: https://orcid.org/0000-0002-9082-506X \\ Centro Universitário de Patos de Minas, Brasil \\ E-mail: patriciapereira@unipam.edu.br
}

\begin{abstract}
Resumo
O ácido hialurônico é uma substância que se torna cada vez mais popular em procedimentos estéticos minimamente invasivos na face. Apesar de o próprio corpo humano possuir ácido hialurônico endógeno, o mesmo torna-se escasso ao longo dos anos com o envelhecimento natural da pele, acarretando em perda de volume e decaimento em toda extensão facial. Dado isso, surgiram os preenchimentos dérmicos de ácido hialurônico os quais possuem capacidade de volumizar tecidos moles e promover harmonia e estética à face. Portanto, este estudo teve por objetivo investigar o conhecimento do uso do ácido hialurônico em intervenções de preenchimento facial levando em consideração suas propriedades, o nível de eficácia e as possíveis complicações. Este estudo consistiu de uma revisão integrativa de caráter básico, qualitativa, descritiva e teve por base as plataformas de pesquisa PubMed e Biblioteca Virtual em Saúde explorando os termos ácido hialurônico, hialuronano, preenchedores dérmicos e estética. Foram incluídos artigos no intervalo de tempo de 2016 a 2021 na língua inglesa e a busca decorreu em 16 artigos. Os artigos selecionados demonstraram que o uso do ácido hialurônico traz ótimos níveis de eficácia e satisfação aos pacientes, porém evidenciaram a necessidade de sessões de retratamento meses depois para manutenção, é seguro, pois as complicações mais comuns cessam em sua maioria, até duas semanas e sem necessidade de intervenção, além de ser uma substância com excelentes propriedades e características reológicas. Pode-se concluir que o uso de ácido hialurônico é eficaz, seguro e possui propriedades ideias em preenchimento dérmico facial.
\end{abstract}

Palavras-chave: Ácido hialurônico; Harmonização orofacial; Preenchimento dérmico; Estética.

\begin{abstract}
Hyaluronic acid is a substance that is becoming increasingly popular in minimally invasive aesthetic procedures on the face. Although the human body itself has endogenous hyaluronic acid, it becomes scarce over the years with the natural aging of the skin, resulting in loss of volume and decay throughout the face. Given this, hyaluronic acid dermal fillers appeared, which have the capacity of volumizing soft tissues and promoting harmony and aesthetics to the face. Therefore, this study aimed to investigate the knowledge of the use of hyaluronic acid in facial filling
\end{abstract}


interventions taking into consideration its properties, the level of effectiveness and possible complications. This study consisted of a basic, qualitative, descriptive integrative review based on the PubMed and Virtual Health Library search platforms, exploring the terms hyaluronic acid, hyaluronan, dermal fillers, and aesthetics. Articles were included in the time range from 2016 to 2021 in the English language and the search yielded 16 articles. The selected articles showed that the use of hyaluronic acid brings great levels of effectiveness and satisfaction to patients, but evidenced the need for retreatment sessions months later for maintenance, it is safe, because the most common complications cease mostly within two weeks and without the need for intervention, besides being a substance with excellent properties and rheological characteristics. It can be concluded that the use of hyaluronic acid is effective, safe and has ideal properties in dermal facial filling.

Keywords: Hyaluronic acid; Hyaluronic harmonization; Dermal fillers; Aesthetics.

\section{Resumen}

El ácido hialurónico es una sustancia cada vez más popular en los procedimientos estéticos mínimamente invasivos en el rostro. Aunque el propio cuerpo humano dispone de ácido hialurónico endógeno, éste va escaseando con el paso de los años con el envejecimiento natural de la piel, lo que provoca una pérdida de volumen y decaimiento en toda la extensión del rostro. Ante esto, aparecieron los rellenos dérmicos de ácido hialurónico, que tienen la capacidad de voluminizar los tejidos blandos y promover la armonía y la estética del rostro. Por lo tanto, este estudio tenía como objetivo investigar el conocimiento del uso del ácido hialurónico en las intervenciones de relleno facial teniendo en cuenta sus propiedades, el nivel de eficacia y las posibles complicaciones. Este estudio consistió en una revisión básica, cualitativa, descriptiva e integradora basada en las plataformas de investigación PubMed y Biblioteca Virtual em Saúde, explorando los términos ácido hialurónico, hialuronano, rellenos dérmicos y estética. Se incluyeron artículos en el intervalo de tiempo de 2016 a 2021 en lengua inglesa y la búsqueda arrojó 16 artículos. Los artículos seleccionados mostraron que el uso del ácido hialurónico aporta grandes niveles de efectividad y satisfacción a los pacientes, pero mostraron la necesidad de sesiones de retratamiento meses después para su mantenimiento, es seguro, pues las complicaciones más comunes cesan en su mayoría en dos semanas y sin necesidad de intervención, además de ser una sustancia con excelentes propiedades y características reológicas. Se puede concluir que el uso del ácido hialurónico es eficaz, seguro y tiene propiedades ideales en el relleno dérmico facial.

Palabras clave: Ácido hialurónico; Armonización hialurónica; Relleno dérmico; Estética.

\section{Introdução}

A estética envolve aspectos multidimensionais, sejam eles objetivos, subjetivos ou culturais, com forte influência sobre a vida humana, pois associa o belo com o sentimento das pessoas. O desejo da boa aparência e duradoura juventude vem impulsionando a busca de produtos e tratamentos estéticos, destarte, a Odontologia contemporânea passa a ser uma área de grande destaque para alcançar tal finalidade, oferecendo procedimentos minimamente invasivos e que restabeleçam função e harmonia (Vasconcelos, et al. 2020).

A Harmonização Orofacial, a mais recente especialidade odontológica, vem crescendo nos dias atuais, sendo cada vez mais desempenhada pelos cirurgiões-dentistas e mais desejada pelos pacientes. Isso devido, principalmente, à divulgação de resultados dos procedimentos nas mídias sociais e também à aceitação da beleza facial como um meio de promoção de qualidade de vida, autoestima e bem-estar psicossocial (McKeown, 2021).

Inicialmente, o conceito de harmonização era bidimensional e limitava-se apenas à eliminação de linhas de expressão e melhora da textura da pele. Hoje, advoga-se uma abordagem tridimensional, ou melhor, do tratamento da face como um todo (Lipko-Godlewska, et al. 2021). Dentre os tratamentos disponíveis, destaca-se o uso dos preenchimentos dérmicos faciais, sendo o ácido hialurônico um dos mais usualmente empregados na atualidade (Fino, et al. 2016).

O ácido hialurônico teve sua descoberta datada em 1934, por Karl Meyer e John Palmer, cientistas da Columbia University, em Nova Iorque, por meio do isolamento da substância presente no corpo vítreo do globo ocular de bovinos (Fallacara, et al. 2018). É um material de origem natural, pertencente ao grupo dos glicosaminoglicanos não sulfatados de alto 
peso molecular e é existente em grande escala no nosso organismo, sendo que a maior parte encontra-se na pele, onde cumpre o objetivo principal de dar volume, sustentação, hidratação, estabilidade e elasticidade (Maytin, 2016).

Apesar de existir no organismo desde o nascimento, o ácido hialurônico se torna escasso ao longo dos anos com o envelhecimento natural da pele, acarretando depressões na derme e perda de volume por sua falta. Assim, esta substância, quando aplicada, detém funções como preenchimento de espaços entre as células, hidratação, lubrificação e estabilização de meios, como também modulação de células inflamatórias (Shin, et al. 2019).

Atualmente, o ácido hialurônico comercial é produzido principalmente pela biotecnologia de fermentação bacteriana, pelo risco quase nulo de induzir resposta imunológica em comparação ao processo de extração de tecidos de animais. Para que o mesmo exerça papel de preenchimento dérmico, além de purificada a substância também é submetida a um processo químico chamado reticulação ou cross-linking (Maia \& Salvi, 2018). É uma técnica que insere substâncias capazes de induzir ligações intermoleculares ao ácido, que minimizam sua toxicidade e aumentam sua resistência à degradação sua retenção in vivo e suas propriedades viscoelásticas (Fagien, et al. 2019).

Outro benefício da aplicação do ácido hialurônico é possuir um antídoto próprio para reverter, ou pelo menos minimizar, sequelas de reações adversas: a enzima hialuronidase (Goodman, et al. 2020). Devido a seu perfil de segurança, durabilidade, previsibilidade, versatilidade e ser minimamente invasivo, tornou-se um dos materiais mais populares para o contorno de tecidos moles e volumização (Choi, 2020).

Desta forma, uma revisão criteriosa sobre essa substância, suas propriedades físico-químicas e reológicas, nível de eficácia, bem como das possíveis complicações, se justifica, pelo interesse cada vez maior de profissionais e pacientes na sua aplicação e por também poder contribuir para minimizar incertezas e possíveis intercorrências no uso do ácido hialurônico em procedimentos de Harmonização Orofacial. Portanto, esta pesquisa foi motivada pela seguinte questão: Por que utilizar a aplicação do ácido hialurônico como técnica de escolha para o preenchimento facial? E a resposta deve levar em consideração suas propriedades, nível de eficácia e segurança.

\section{Metodologia}

Trata-se de uma revisão integrativa da literatura, de abordagem qualitativa, cuja classificação se dá por finalidade básica pura, por objetivo descritiva e modalidade bibliográfica (Estrela, 2018).

Para o estudo em questão, adotou-se a estratégia PICO, em que foi atribuído ao P (problema) a necessidade de preenchimento facial, ao I (intervenção) a aplicação do ácido hialurônico, ao C (comparação) o preenchimento facial com outros biomateriais e ao elemento $\mathrm{O}$ (outcome ou desfecho) os resultados oferecidos pelas propriedades físico-químicas e reológicas do ácido hialurônico e sua eficácia, bem como as eventuais complicações de seu uso como produto para preenchimento facial.

Para a realização da revisão integrativa da literatura foram buscados artigos utilizando as bases de dados eletrônicas: PubMed (National Library of Medicine) e Biblioteca Virtual em Saúde (BVS) - Medline, LILACS e Scielo. Foram considerados quatro palavras-chave para elaboração da estratégia de busca: "ácido hialurônico", "hialuronano", "preenchedores dérmicos", "estética". Em seguida, na opção pesquisa avançada, cruzaram-se os termos, combinando-os com operadores booleanos "AND" e "OR".

Assim, foram dois os descritores utilizados para a pesquisa nas duas plataformas, resultando em "ácido hialurônico OU hialuronano E preenchedores dérmicos" e "ácido hialurônico OU hialuronano E estética" bem como seus respectivos termos em inglês "hyaluronic acid OR hyaluronan AND dermal fillers" e "hyaluronic acid OR hyaluronan AND esthetic".

Como critérios de inclusão, foram selecionados artigos publicados entre o dia 1 de janeiro de 2016 até 1 de junho de 2021, dos idiomas de língua inglesa e portuguesa, disponíveis nas bases de dados de pesquisa descritas anteriormente. 
Foram excluídos da pesquisa artigos de outros idiomas, artigos que não possuíam texto completo disponível na íntegra, artigos apresentados em forma de resumos e opiniões de especialistas.

Foram selecionados os artigos observando-se os seguintes desfechos: Propriedades físico-químicas e reológicas do ácido hialurônico, eficácia do uso do ácido hialurônico e complicações do uso do ácido hialurônico em preenchimentos faciais.

\section{Resultados}

A coleta dos dados resultou na identificação de 737 artigos potencialmente elegíveis. Foram eliminados, em primeira análise, 145 artigos duplicados identificados por meio do registro dos títulos em documentos do Word. Durante a leitura dos títulos dos materiais escalados, considerando-se os critérios de inclusão e exclusão, foram eliminadas 344 publicações. Já no decurso da análise dos resumos dos artigos, após a leitura de um por um, eliminou-se mais 203 artigos, basicamente pelo fato das temáticas abordadas desviarem dos objetivos da pesquisa, como também por apresentarem-se como resumos ou opiniões de especialistas.

Em seguida, decorreu-se a leitura completa dos artigos na íntegra, em que 29 artigos foram eliminados. Aceitaram-se artigos que respondessem a pelo menos um dos três desfechos, desde que de maneira clara e objetiva. Porém, houve predileção àqueles artigos que respondessem a dois desfechos, àqueles com um maior nível de evidência e a estudos clínicos de maior durabilidade e alto número amostral. A revisão abrangeu estudos clínicos nos mais diversos locais da face, respeitando o princípio do tratamento da face como um todo, incluindo-se estudos sobre preenchimento nos lábios, nas dobras do terço médio da face (dobras nasolabiais), no terço inferior da face (mandíbula e queixo), no terço médio facial e na região infraorbital. Artigos de preenchimento em nariz apresentavam-se, por sua maioria, como relatos de caso ou associados com rinoplastia, logo, não foram incluídos no estudo.

Desta forma, alcançou-se a amostra final de 16 estudos (Figura 1), que, após a leitura na íntegra, foram organizados para análise e interpretação dos resultados. Todos foram publicados entre 2016 e 2021. Duas tabelas com a síntese dos resultados foram elaboradas (Tabela 1 e Tabela 2).

A decisão da confecção de duas tabelas se deu por grande parte dos estudos analisados na Tabela 1 não apontarem, de maneira clara e completa, o desfecho de "propriedades" do ácido hialurônico. Assim, neste primeiro quadro, os desfechos foram "nível de eficácia” e "complicações" do uso do ácido hialurônico.

Da mesma maneira, a Tabela 2 é composta por artigos em que não foi possível a inclusão do desfecho "nível de eficácia", visto que nos estudos não havia metodologia específica para o cálculo da eficácia do ácido hialurônico por meio de escalas como Global Aesthetic Improvement Scale (GAIS), Questionário FACE-Q, Wrinkle Severity Rating Scale (WSRS), dentre outras, portanto, inclui-se os desfechos "propriedades" e "complicações".

Já para o desfecho "complicações", a maior parte dos artigos selecionados trazia informações relevantes, portanto, houve inclusão em ambas as tabelas. 
Figura 1: Fluxograma do processo de busca na literatura.
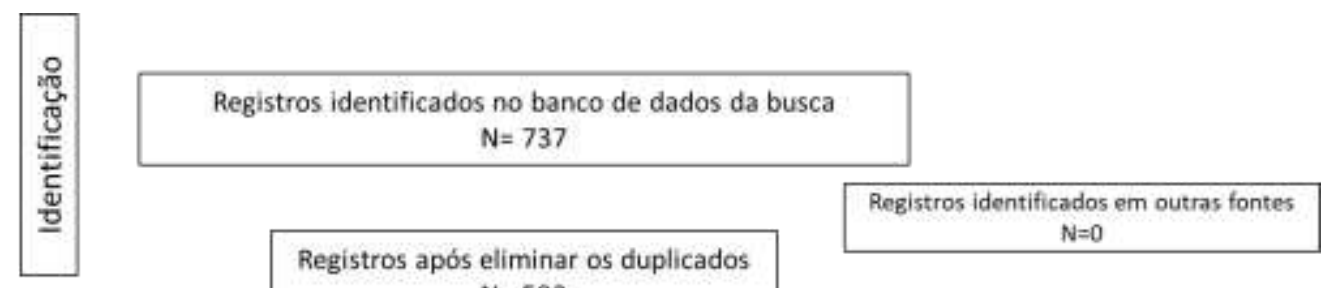
$\mathrm{N}=592$
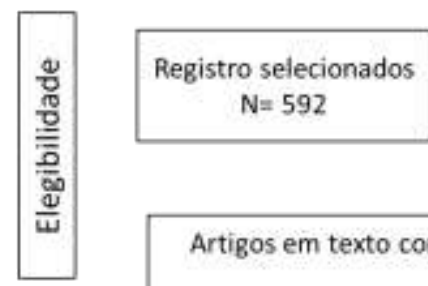

Registros excluidos $\mathrm{N}=547$

Artigos em texto completo avaliados para elegibilidade $N=45$

Fonte: Autores.

Tabela 1 - Caracterização dos estudos clínicos, segundo autor principal/ano, periódico, escala de eficácia (método), eficácia follow-up e complicações.

\begin{tabular}{|c|c|c|c|c|}
\hline $\begin{array}{l}\text { Autor } \\
\text { principal/ano }\end{array}$ & Períodico & $\begin{array}{l}\text { Escala de } \\
\text { eficácia } \\
\text { (método) }\end{array}$ & Eficácia - follow up & Complicações \\
\hline Rzany et al., 2016. & $\begin{array}{l}\text { American } \\
\text { Society for } \\
\text { Dermatologic } \\
\text { Surgery }\end{array}$ & WSRS & $\begin{array}{l}70 \% \text { dos indivíduos houve melhora } \\
\text { pelo menos de } 2 \text { graus; estendendo } \\
\text { até o mês } 18 \text { (retratamento feito no } \\
\text { mês } 9 \text { ). }\end{array}$ & $\begin{array}{l}\text { Edemas, hematomas e nódulos não } \\
\text { necessitaram intervenção, pois foram } \\
\text { resolvidos em pelo menos um mês, } \\
\text { exceto } 1 \text { evento de telangiectasia. }\end{array}$ \\
\hline Wu et al., 2016. & $\begin{array}{l}\text { Arch Dermatol } \\
\text { Res }\end{array}$ & $\begin{array}{l}\text { WSRS } \\
\text { GAIS }\end{array}$ & $\begin{array}{l}\text { Mês } 6 \text { - } 100 \% \text { de melhoria em ambos } \\
\text { os lados; meses } 13-15-60 \% \text { de } \\
\text { melhoria com BioHyalux e } 64 \% \text { com } \\
\text { Restylane. }\end{array}$ & $\begin{array}{l}\text { Inchaço, dor, coceira, hematoma e } \\
\text { sensibilidade no local da injeção, } \\
\text { resolvidos em } 1 \text { semana sem } \\
\text { tratamento. }\end{array}$ \\
\hline Niforos et al., 2017. & $\begin{array}{l}\text { American } \\
\text { Society for } \\
\text { Dermatologic } \\
\text { Surgery }\end{array}$ & $\begin{array}{l}\text { AIRS } \\
\text { Questionário } \\
\text { PAAQ } \\
\text { GAIS }\end{array}$ & $\begin{array}{l}\text { Mês } 1-99,3 \% \text { dos olhos alcançaram } \\
\text { pelo menos } 1 \text { ou maior grau de } \\
\text { melhoria; } 87,8 \% \text { pelo menos } 2 \text { graus } \\
\text { da escala de melhoria; mês } 6-92 \% \\
\text { em pelo menos } 1 \text { grau de melhoria; e } \\
\text { mês } 12-54 \% \text { em pelo menos } 1 \text { grau } \\
\text { de melhoria. }\end{array}$ & $\begin{array}{l}\text { Reações locais de hematomas (3\% } \\
\text { dos olhos), inchaços }(3 \%) \text {, } \\
\text { vermelhidão }(2 \%) \text {, edema }(2 \%) \text { e dor } \\
(1 \%) \text {. Nenhum foi classificado como } \\
\text { grave e a maioria foi resolvida até o } \\
\text { dia } 14 \text {. Edemas leves a moderados } \\
\text { de início tardio foram observados em } \\
\text { (11\%) dos olhos no mês } 6 \text {. Efeito } \\
\text { Tyndall observado no mês } 6 \text { em } 3 \\
\text { indivíduos }(4 \%) \text {. }\end{array}$ \\
\hline $\begin{array}{l}\text { Stojanovič } \quad \text { L., } \\
\text { Majdič N., 2018. }\end{array}$ & $\begin{array}{l}\text { Journal } \\
\text { Cosmetic } \\
\text { Dermatologic }\end{array}$ & $\begin{array}{l}\text { NLFS } \\
\text { ALFS } \\
\text { LFGS } \\
\text { CQCS } \\
\text { FACE-Q } \\
\text { GAIS } \\
\text { NRS } \\
\text { LFS }\end{array}$ & $\begin{array}{l}\text { Mês 1: eficácia entre } 71 \% \text { e } 93.2 \% \text {. } \\
\text { Mês } 12 \text { meses eficácia entre } 48.3 \% \text { e } \\
60 \% \text {. Os resultados mostraram que } \\
\text { os sujeitos ficaram "satisfeitos" ou } \\
\text { "muito satisfeitos" com o aumento } \\
\text { dos lábios. }\end{array}$ & $\begin{array}{l}\text { A maioria dos indivíduos relataram } \\
\text { como leves (variação de } 71 \%-88 \% \text { ) } \\
\text { como: inchaço, contusão, hematoma, } \\
\text { dor, vermelhidão e coceira ou } \\
\text { complicações moderadas (variação } \\
\text { de } 11 \%-16 \% \text { ). }\end{array}$ \\
\hline
\end{tabular}




\begin{tabular}{|c|c|c|c|c|}
\hline Vandeputte, 2018. & $\begin{array}{l}\text { Journal of } \\
\text { Clinical and } \\
\text { Aesthetic } \\
\text { Dermatology }\end{array}$ & GAIS & $\begin{array}{l}\text { Mês } 1 \text { - 96,2\% consideraram sua } \\
\text { aparência melhorada; mês } 6-94,9 \% \\
\text { estavam satisfeitos com os resultados } \\
\text { e em longo prazo (média: } 3,2 \text { anos) - } \\
74,9 \% \text { se mantiveram satisfeitos. }\end{array}$ & $\begin{array}{l}\text { Inchaço } 30 \%, \text { nódulo } 27 \% \text {, } \\
\text { hematoma } 20 \% \text {, dureza } 15 \% \text {, } \\
\text { vermelhidão } 14 \% \text {, descoloração } 4 \% \\
\text { e coceira } 1 \% \text {. }\end{array}$ \\
\hline Wang et al., 2018. & $\begin{array}{l}\text { International } \\
\text { Society of } \\
\text { Aesthetic } \\
\text { Plastic Surgery }\end{array}$ & VAS & $\begin{array}{l}\text { Relacionado à dor: grupo com } \\
\text { lidocaína foi muito menor do que } \\
\text { para o grupo sem lidocaína. } \\
\text { Relacionado à eficácia dos produtos, } \\
\text { não houve diferença significativa } \\
\text { entre os dois grupos. }\end{array}$ & $\begin{array}{l}\text { Complicações como edema, eritema, } \\
\text { hematomas, coceira e endurecimento } \\
\text { foram relatadas. As composições } \\
\text { com lidocaína aliviam quadros de } \\
\text { dor e aumentam satisfação. }\end{array}$ \\
\hline Ogilvie et al., 2020. & $\begin{array}{l}\text { Aesthetic } \\
\text { Surgery Journal }\end{array}$ & $\begin{array}{l}\text { GAIS } \\
\text { Questionário } \\
\text { FACE-Q G }\end{array}$ & $\begin{array}{l}\text { Mês } 1 \text { e } 3: \text { : } 100 \% \text { dos participantes } \\
\text { relataram "melhora" ou "muita } \\
\text { melhora"; mês } 18,52,5 \% \text { ainda } \\
\text { relataram "melhora" ou "muita } \\
\text { melhora" e mês } 1 \text { após o } \\
\text { retratamento (realizado no mês 18) } \\
96,9 \% \text { voltaram a relatar "melhora" } \\
\text { ou "muita melhora". }\end{array}$ & $\begin{array}{l}20,2 \% \text { dos indivíduos relataram: } \\
\text { dureza e sensibilidade ao toque, } \\
\text { vermelhidão, dor, nódulos, } \\
\text { descoloração e coceira. }\end{array}$ \\
\hline Jung et al., 2021. & $\begin{array}{l}\text { Dermatologic } \\
\text { Therapy }\end{array}$ & $\begin{array}{l}\text { MFVDS } \\
\text { GAIS }\end{array}$ & $\begin{array}{l}\text { Mês 9: SHAPE-NVL eficácia de } \\
81,93 \% \text { e VYC-20L de } 85,54 \% \text {. Mês } \\
\text { 12: SHAPE-NVL } 80,72 \% \text { e VYC- } \\
\text { 20L de } 81,92 \% \text {. Aos } 24 \text { meses, as } \\
\text { taxas de respondentes foram } 73,91 \% \\
\text { para SHAPE-NVL e } 72,46 \% \text { para } \\
\text { VYC-20L. }\end{array}$ & $\begin{array}{l}\text { A incidência de complicações foram } \\
\text { de } 51,14 \% \text { para ambos os produtos. } \\
\text { Edema no local da injeção, dureza } \\
\text { local e dor foram os mais } \\
\text { comumente relatados. Todos foram } \\
\text { de gravidade leve a moderada. } \\
\text { Houve um caso de inchaço tardio } \\
\text { após } 28 \text { semanas do tratamento. }\end{array}$ \\
\hline
\end{tabular}

Fonte: Autores.

Tabela 2 - Caracterização dos estudos, segundo autor principal/ano, periódico, tipo de estudo (método), propriedades e complicações.

\begin{tabular}{|c|c|c|c|c|}
\hline $\begin{array}{c}\text { Autor } \\
\text { principal/ano }\end{array}$ & Períodico & $\begin{array}{l}\text { Tipo de } \\
\text { estudo } \\
\text { (método) }\end{array}$ & Propriedades & Complicações \\
\hline $\begin{array}{l}\text { Ciccone V., } \\
\text { Zazzetta M., } \\
\text { Morbidelli L., } \\
2019 .\end{array}$ & Cells & $\begin{array}{l}\text { Análises in } \\
\text { vitro e in vivo }\end{array}$ & $\begin{array}{l}\text { Biocompatibilidade, ativação de células } \\
\text { inflamatórias, hidrofílico, efeito hidratante, } \\
\text { integração tecidual, proliferação celular, } \\
\text { comportamento pró-angiogênico transitório e } \\
\text { capacidade de levantamento (preenchimento). }\end{array}$ & - \\
\hline Fagien et al., 2019. & $\begin{array}{l}\text { Plastic and } \\
\text { Reconstructive } \\
\text { Surgery }\end{array}$ & $\begin{array}{l}\text { Análises in } \\
\text { vitro }\end{array}$ & $\begin{array}{l}\text { Viscoelasticidade (viscoso }+ \text { elástico), } \\
\text { capacidade de espalhamento, natural durante a } \\
\text { dinâmica facial, integração tecidual, resistência } \\
\text { ao cisalhamento, coesividade, fator de inchaço e } \\
\text { hidrofílico, características que o particularizam } \\
\text { quanto ao seu uso clínico. }\end{array}$ & - \\
\hline $\begin{array}{l}\text { La Gatta et al., } \\
2019 .\end{array}$ & PLOS ONE & $\begin{array}{l}\text { Análises in } \\
\text { vitro }\end{array}$ & $\begin{array}{l}\text { Características hidrodinâmicas: hidrossolúvel e } \\
\text { hidrofílico; viscoelasticidade, coesividade, } \\
\text { biodegradável, capacidade de estimular } \\
\text { colágeno I, elastina e aquaporina3; regeneração, } \\
\text { hidratação e ação física volumétrica } \\
\text { (preenchimento). }\end{array}$ & - \\
\hline Lee et al., 2019. & $\begin{array}{l}\text { American } \\
\text { Society for } \\
\text { Dermatologic } \\
\text { Surgery }\end{array}$ & $\begin{array}{l}\text { Análise in } \\
\text { vitro de } \\
\text { propriedades } \\
\text { reológicas }\end{array}$ & $\begin{array}{l}\text { Variação considerável das amostras entre a } \\
\text { concentração de ácido hialurônico, elasticidade, } \\
\text { viscosidade, padrão de espalhamento, } \\
\text { capacidade de volumização, grau de reticulação, } \\
\text { durabilidade, hidrofilicidade, que por sua vez } \\
\text { impacta na estrutura molecular e desempenho } \\
\text { clínico. }\end{array}$ & $\begin{array}{l}\text { Reações alérgicas } \\
\text { imediatas e tardias. }\end{array}$ \\
\hline
\end{tabular}




\begin{tabular}{|c|c|c|c|c|}
\hline Cabral et al., 2020. & $\begin{array}{l}\text { Clinical, } \\
\text { Cosmetic and } \\
\text { Investigational } \\
\text { Dermatology }\end{array}$ & $\begin{array}{l}\text { Análises } \\
\text { comparativas } \\
\text { in vitro e in } \\
\text { vivo }\end{array}$ & $\begin{array}{l}\text { Às } 72 \text { h do estudo, houve alta proliferação } \\
\text { celular para o ácido hialurônico. Revelou-se } \\
\text { alto teor de colágeno tipo I em comparação com } \\
\text { Ácido poli-L-láctico (PLLA). Observou-se } \\
\text { também que o preenchimento dérmico PLLA } \\
\text { teve um efeito potencialmente desfavorável no } \\
\text { fenótipo do fibroblasto, com possíveis } \\
\text { complicações clínicas, ao contrário do ácido } \\
\text { hialurônico. }\end{array}$ & Reações inflamatórias. \\
\hline $\begin{array}{l}\text { La Gatta et al., } \\
2020 .\end{array}$ & $\begin{array}{l}\text { Clinical, } \\
\text { Cosmetic and } \\
\text { Investigational } \\
\text { Dermatology }\end{array}$ & $\begin{array}{l}\text { Análises in } \\
\text { vitro e estudo } \\
\text { clínico }\end{array}$ & $\begin{array}{l}\text { Coesividade, elasticidade, viscosidade, } \\
\text { biodegradável, reversibilidade (radicais livres e } \\
\text { hialuronidase), hidrofílico, capacidade de } \\
\text { hidratação, integração tecidual, ação } \\
\text { volumétrica } \\
\text { biocompatibilidade, durabilidade e satisfação } \\
\text { de, pelo menos, } 12 \text { meses. }\end{array}$ & $\begin{array}{l}20 \% \text { apresentaram leve } \\
\text { eritema na área injetada } \\
\text { que desapareceu em } 30 \\
\text { minutos e edema foi } \\
\text { observado em } 7 \text { casos no } \\
\text { entanto, diminuiu } \\
\text { espontaneamente em } 72 \\
\text { horas. }\end{array}$ \\
\hline $\begin{array}{l}\text { Nakab L., Hee C. } \\
\text { K., Guetta, O., } \\
2020 .\end{array}$ & $\begin{array}{l}\text { PRS Global } \\
\text { Open }\end{array}$ & $\begin{array}{l}\text { Cultura } \\
\text { celular in vivo }\end{array}$ & $\begin{array}{l}\text { Hidratação, capacidade hidrofílica, efeito } \\
\text { proliferativo de células, aumento na densidade } \\
\text { de colágeno, na expressão de fibrina- } 2 \text {, } \\
\text { aquaporina-3 e no conteúdo de } \\
\text { glicosaminoglicanos da pele. Sem alterações na } \\
\text { expressão de elastina. }\end{array}$ & - \\
\hline $\begin{array}{l}\text { Cannella et al., } \\
2021 .\end{array}$ & $\begin{array}{l}\text { BioMed } \\
\text { Research } \\
\text { International }\end{array}$ & $\begin{array}{l}\text { Ensaio de } \\
\text { citotoxidade } \\
\text { em células } \\
\text { L929 }\end{array}$ & $\begin{array}{l}\text { Nenhum dos preenchimentos tiveram efeitos } \\
\text { citotóxicos em } 24 \mathrm{~h}, 48 \mathrm{~h} \text { e } 72 \mathrm{~h} \text {. Portanto, } \\
\text { natural, reversível, biodegradável, não tóxico, } \\
\text { não cancerígeno, inerte, não alérgico, não } \\
\text { imunogênico, não pirogênico, biocompatível, } \\
\text { boa durabilidade e auxiliar na proliferação } \\
\text { celular. }\end{array}$ & $\begin{array}{l}\text { Inflamação aguda e/ou } \\
\text { crônica, devido à rejeição. }\end{array}$ \\
\hline
\end{tabular}

Fonte: Autores

\section{Discussão}

A percepção dos resultados desta revisão de literatura vai ao encontro a Bukhari, et al. (2018), que afirmam que os preenchedores dérmicos de ácido hialurônico são cada vez mais populares para o aumento de tecidos moles e rejuvenescimento, porque oferecem uma forma menos invasiva de melhora na estética facial e com menos tempo de inatividade do que intervenções cirúrgicas. Da mesma maneira, Choi (2020), reitera que o ácido hialurônico é um dos mais usuais preenchedores dérmicos disponíveis na atualidade em razão de sua eficácia e ideais propriedades de volumização.

Diferentes autores, comparando diferentes produtos, exibem trabalhos que avaliaram o grau de satisfação dos pacientes submetidos a intervenções difusas na face. No estudo clínico retrospectivo de longa duração executado por Vandeputte (2018), no qual o autor utilizou a escala de avaliação Global Aesthetic Improvement Scale (GAIS) para cálculo de melhoria estética, foram investigados 110 pacientes submetidos a procedimentos de preenchimento facial em face toda com ácido hialurônico. Constatou-se que mesmo após 3,2 anos do tratamento, 74,9\% dos indivíduos permaneciam satisfeitos com o resultado. Em outro estudo de longa duração de Jung, et al. (2021), em que compararam os resultados de dois produtos, obtiveram que no mês 24 as taxas de satisfação quanto ao tratamento de regiões da face média (bochechas e zigomático), alcançaram 73,91\% para o preenchimento com Neuramis Volume Lidocaine (SHAPE-NVL) e 72,46\% para Voluma with Lidocaine (VYC-20L). São resultados muito próximos entre si e em alto patamar, obtidos de observações em longo prazo.

Em contrapartida, na revisão sistemática de Stojanovic, et al. (2018), que analisaram ensaios clínicos de eficácia de preenchimentos restritos aos lábios, após 12 meses do tratamento inicial de 52,5\% a 64\% dos participantes ainda demonstravam satisfação. Pode-se supor, atualizando argumentos de Michaud, et al. (2016), que tal variação dos resultados se deva ao tipo de produto utilizado, alguns já obsoletos, bem como ao local, quantidade e profundidade da aplicação. Não se 
pode deixar de considerar que quanto menores as quantidades de produtos necessários e a profundidade da aplicação, menor será a durabilidade da intervenção. Assim, explicam-se resultados mais positivos e longevos em tratamentos mais abrangentes de estruturas faciais ou em face toda.

Dada a reversibilidade natural do ácido hialurônico, a prática de reforço periódico também merece considerações. No estudo conduzido por Rzany, et al. (2016), 70\% dos indivíduos se mantiveram satisfeitos com o tratamento de sulcos nasolabiais no mês 18, de acordo com a escala avaliativa Wrinkle Severity Rating Scale (WSRS). Nestes pacientes foi realizado um retratamento ao nono mês, após a primeira aplicação. Já no trabalho de Ogilvie, et al. (2020), após 18 meses sem reintervenção cerca de apenas 52,5\% dos indivíduos ainda relataram satisfação com o tratamento de preenchimento de mandíbula e mento e com o retratamento, realizado nesse mesmo período, 96,9\% dos indivíduos manifestaram-se satisfeitos. É importante destacar que o volume necessário para o retratamento foi aproximadamente de dois terços da quantidade total utilizada na primeira aplicação. Portanto, sessões de retratamento alguns meses depois da última aplicação são essenciais para a manutenção dos resultados e satisfação dos pacientes, em razão da característica de reversibilidade, bem explicada por La Gatta, et al. (2020) em que é biodegradável, ou seja, com o passar dos meses é absorvido pela hialuronidase endógena ou catabolizado pela oxidação danosa de espécies reativas de oxigênio presentes nos tecidos.

Outro aspecto que merece discussão diz respeito à capacidade do produto de preenchimento de resistir às deformações. Como explicitado por Fagien, et al. (2019), em suas análises in vitro, o ácido hialurônico para preenchimento dérmico, em padrões reológicos, deve se apresentar viscoelástico, ou seja, precisa combinar um componente de viscosidade, que o deforme e que possibilite sua injeção através de uma agulha ou cânula, com um componente de elasticidade, que viabilize o retorno da substância à sua forma original após a aplicação, além de fornecer durabilidade de correção, resistência às forças de cisalhamento e retenção in vivo.

Um importante trabalho a ser referenciado, relativo a este aspecto, é o de Heitmiller, et al. (2021), que resume em 4 os parâmetros reológicos primários que descrevem as propriedades viscoelásticas: G’ (módulo de elasticidade), G” (módulo de viscosidade), $\mathrm{G} *$ (módulo de cisalhamento), e tan $\delta$ (medida da relação entre as propriedades viscosa e elástica). Segundo os autores, $\tan \delta<1$ indica que o material é principalmente elástico e tipo gel, enquanto que $\tan \delta>1$ aponta para um material principalmente viscoso. Em preenchimentos de ácido hialurônico, o valor de $\tan \delta$ normalmente varia de 0,05 a 0,80, demonstrando ser uma substância de característica mais elástica sob tensões teciduais.

Contribuindo para este tópico da discussão, o estudo de Lee, et al. (2019) que mensurou as propriedades reológicas de 41 preenchedores dérmicos faciais de ácido hialurônico, constatou que as propriedades de todos os preenchimentos variaram em termos de concentração de ácido hialurônico, força de injeção durante a administração, tamanho de partícula e propriedades reológicas. Pode-se atribuir o destaque que esses autores deram à importância do parâmetro do módulo de elasticidade na indicação clínica do produto ao argumento de que quanto maior este valor mais alta será a resistência à deformação, constituindo-se, portanto, em especial indicação para contorno e preenchimento de áreas mais profundas. Consequentemente, os preenchimentos de ácido hialurônico com baixa elasticidade demonstram menos viscososidade, conferindo maior espalhabilidade no tecido após sua injeção e proporcionando um efeito hidrolift, sendo recomendado para hidratação e preenchimento de locais mais superficiais da pele da face.

Com relação à propriedade hidrofílica, depreende-se do trabalho de Rohrich, et al. (2019) que a viscoelasticidade tende a aumentar com altos níveis de reticulação, e isto proporciona maior resistência à degradação e durabilidade ao ácido hialurônico, a despeito da sustentação de Herrmann, et al. (2018), para quem altas percentagens de reticulação tendem a diminuir a hidrofilicidade do produto. A característica hidrofílica da substância, em conformidade com Fallacara, et al. (2018), advém do arranjo estrutural da molécula do ácido hialurônico se dar de uma região central apolar, relativamente hidrofóbica, envolta por cadeias periféricas que se configuram polares. Por possuir tal particularidade é que KRUK, et al. (2019) atribuem 
ao ácido hialurônico as características hidrodinâmicas essenciais de hidratação, restabelecimento de volume nas camadas intradérmicas e melhora na qualidade e aparência da pele.

Em um comparativo do estudo de cultura celular in vivo, de Nakab, et al. (2020), e o estudo de análise in vitro, desenvolvido por La Gatta, et al. (2019), aponta convergência de resultados para a amplificação da capacidade hidratante do ácido hialurônico a partir da interação com as células da pele e do tecido conjuntivo subjacente, verificada pela ativação de fibroblastos, estimulação de colágeno tipo I e aquaporina-3, que determinaram um efeito proliferativo e regenerativo de células dérmicas e subdérmicas.

Além da interação e integração tecidual, outras importantes propriedades do ácido hialurônico podem ser arroladas a partir da leitura dos trabalhos de Ciccone, et al. (2019), Cabral, et al. (2020) e Cannella, et al. (2020), sendo elas a biocompatibilidade, a não toxicidade e a indução de um comportamento pró-angiogênico transitório. É possível estabelecer como fator coadjuvante de tais propriedades uma leve reação inflamatória na fronteira do tecido hospedeiro, que acontece logo após a aplicação do produto e que é seguida por um crescimento fibroso gradual interno. Em verdade, este fenômeno culmina em contribuir para a integração tecidual, pois que oferece suporte ao gel, ancorando-o ao tecido circundante do hospedeiro e evitando, assim, tanto migração como rejeição da substância.

Por fim, sobre as eventuais complicações que podem os pacientes passar após a injeção de ácido hialurônico, como demonstrados nos ensaios clínicos randomizados de Ogilvie, et al. (2020) e Jung, et al. (2021) que esses problemas se apresentam em torno de 20,2\% a 51,14\% dos casos. Dentre as reações adversas relatadas nos estudos, as mais comumente encontradas foram dor no local de aplicação, vermelhidão, edema, eritema, dureza, nódulos, coceira e hematoma. Já casos de telangiectasia, reações alérgicas imediatas, reações alérgicas tardias, inflamações agudas e inflamações crônicas, assim como efeito Tyndall, que se refere a uma coloração azulada na pele, foram encontrados em menor frequência.

Singh e Nooreyezdan (2020) relataram que eritema, edema, inchaço, hematomas, dor e coceira são comuns e ocorrem quase imediatamente após as injeções. Pode-se inferir que essas complicações sejam causadas por lesão das estruturas dérmicas e ocasional ruptura de vasos sanguíneos durante a injeção da substância. Até porque, segundo o estudo de Wu, et al. (2016), a grande maioria desses eventos adversos resolvem-se em até 2 semanas e sem necessidade de qualquer tipo de tratamento. Como precaução, durante a aplicação, Wollina e Goldman (2020) afirmam que o clínico deve tomar cuidado redobrado no entorno das regiões temporal, glabelar e do supercílio. A recomendação desses autores é respaldada pela condição anatômica dessas regiões, cujos vasos apresentam anastomoses com estruturas vasculares intracranianas, como o seio cavernoso e os seios da dura-máter, desprovidas de válvulas e sujeitas a fluxo e contrafluxo dependente do gradiente de pressão. Naturalmente, uma injeção de qualquer conteúdo nessa região facial determina uma diferença de pressão favorável à disseminação da substância para a vizinhança, inclusive áreas encefálicas. Ainda que limitadas às áreas extracarnianas, caso haja injeção intravascular ou embolia, há a possibilidade de necrose tecidual e até mesmo cegueira, se afetada a artéria oftálmica (Sito, Manzoni \& Sommariva, 2019).

Assim, é imprescindível que o clínico tenha controle sobre a técnica de injeção, profundidade, volume, velocidade e precisão, além, incontestavelmente, do profundo conhecimento da anatomia facial, para que o risco de desenvolvimento de complicações seja diminuído. Perda de visão, formações de cicatrizes e necrose são complicações vasculares temidas e segundo Singh e Nooreyezdan (2020) estão em alarmante aumento de suas incidências, como reflexo da progressão exponencial de procedimentos de preenchimento com ácido hialurônico realizados nos últimos anos. Felizmente, como atenuante, o ácido hialurônico possui, na condição de elemento fisiológico, o já mencionado antídoto igualmente natural e que também pode ser sintetizado em laboratório: a hialuronidase. Em havendo persistência de problemas, conforme orientam Buhren, et al. (2016), a hialuronidase pode "quebrar" o preenchimento, desencadeando um processo de despolimerização do ácido hialurônico e transformando-o em uma forma mais permeável e mais bem absorvível pelos tecidos. 


\section{Conclusão}

Conclui-se que os preenchimentos dérmicos de ácido hialurônico estão revolucionando os métodos de devolver estética, confiança e autoestima aos pacientes, em seu princípio de harmonização da face como um todo. Apesar de seu caráter temporário, possuem ótimos níveis de eficácia e satisfação aos primeiros meses após a aplicação, dos quais podem ser mantidos por 12 meses ou mais, variando conforme a área anatômica tratada e do produto de ácido hialurônico utilizado. É, portanto, um tratamento vantajoso por ser minimamente invasivo e reversível.

O ácido hialurônico possui propriedades e características reológicas ideias para o tratamento de preenchimento dérmico na face. É seguro, pois as complicações mais comuns cessam, em sua maioria, em até duas semanas e sem necessidade de intervenção. Porém, deve-se atentar às raras e graves complicações que podem deixar sequelas irreversíveis. Daí a importância da correta habilitação do profissional na área, do profundo conhecimento da anatomia da face, das técnicas aplicadas e dos produtos disponíveis para o preenchimento e eventual necessidade de reversão.

Mais estudos nessa área são necessários, pois se apresenta como um assunto atual, que tem crescido e se popularizado muito nos últimos anos, devido a grande demanda e busca pela harmonização facial estética e funcional. Portanto, para que seja realizado procedimentos com mais segurança, é necessário entender mais sobre os mecanismos dos preenchedores exógenos na face humana.

\section{Referências}

Buhren, B. A., Schrumpf, H., Hoff, N. P., Bölke, E., Hilton, S. \& Gerber P. A. (2016). Hyaluronidase: from clinical applications to molecular and cellular mechanisms. Eur J Med Res., 21, 5.

Bukhari, S. N. A., Roswandi, N. L., Waqas, M., Habib, H., Hussain, F., Khan, S., Sohail, M., Ramli, N. A., Thu, H. E. \& Hussain, Z. (2018). Hyaluronic acid, a promising skin rejuvenating biomedicine: A review of recent updates and pre-clinical and clinical investigations on cosmetic and nutricosmetic effects. Int $J$ Biol Macromol., 120, 1682-1695.

Cabral, L. R. B., Teixeira, L. N., Gimenez, R. P., Demasi, A. P. D., de Brito Junior, R. B., de Araújo, V. C. \& Martinez, E. F. (2020). Effect of Hyaluronic Acid and Poly-L-Lactic Acid Dermal Fillers on Collagen Synthesis: An in vitro and in vivo Study. Clin Cosmet Investig Dermatol., 13, 701-710.

Cannella, V., Altomare, R., Leonardi, V., Russotto, L., Di Bella, S., Mira, F. \& Guercio, A. (2020). In Vitro Biocompatibility Evaluation of Nine Dermal Fillers on L929 Cell Line. Biomed Res Int., 21.

Choi, M. S. (2020). Basic rheology of dermal filler. Arch Plast Surg., 47(4), 301-304.

Ciccone, V., Zazzetta, M. \& Morbidelli, L. (2019). Comparison of the Effect of Two Hyaluronic Acid Preparations on Fibroblast and Endothelial Cell Functions Related to Angiogenesis. Cells, 8(12), 1479.

Estrela, C. (2018). Metodologia Científica: Ciência, Ensino, Pesquisa. Editora Artes Médicas.

Fagien, S., Bertucci, V., Von Grote, E. \& Mashburn, J. H. (2019). Rheologic and Physicochemical Properties Used to Differentiate Injectable Hyaluronic Acid Filler Products. Plast Reconstr Surg., 143(4), 707-720.

Fallacara, A., Baldini, E., Manfredini, S. \& Vertuani, S. (2018). Hyaluronic Acid in the Third Millennium. Polymers (Basel), $10(7), 701$.

Fino, P., Maruccia, M., Ciotti, M., Amorosi, V \& Scuderi, N. (2016). Patient satisfaction as an excellent track record in nonsurgical rejuvenation procedures. Eur Rev Med Pharmacol Sci., 20(10), 1911-1917.

Goodman, G. J., Liew, S., Callan, P. \& Hart, S. (2020). Facial aesthetic injections in clinical practice: Pretreatment and posttreatment consensus recommendations to minimise adverse outcomes. Australas J Dermatol., 61(3), 217-225.

Heitmiller, K., Ring, C. \& Saedi, N. (2021). Rheologic properties of soft tissue fillers and implications for clinical use. J Cosmet Dermatol., 20(1), 28-34.

Herrmann, J. L., Hoffmann, R. K., Ward, C. E., Schulman, J. M. \& Grekin, R. C. (2018). Biochemistry, Physiology, and Tissue Interactions of Contemporary Biodegradable Injectable Dermal Fillers. Dermatol Surg., 44, 19-31.

Jung, J. M., Lee, W. S., Yoon, J., Paik, S. H., Han, H. S., Lee, W. J., Chang, S. E., Won, C. H. \& Kim, B. J. (2021). A multicenter, randomized, double-blind comparison of two hyaluronic acid fillers in mid-face volume restoration in Asians: A 2-year extension study. Dermatol Ther., $34(2), 14787$.

Kruk, D., Rochowski, P., Masiewicz, E., Wilczynski, S., Wojciechowski M., Broche, L. M. \& Lurie, D. J. (2019). Mechanism of Water Dynamics in Hyaluronic Dermal Fillers Revealed by Nuclear Magnetic Resonance Relaxometry. Chemphyschem., 20(21), $2816-2822$.

La Gatta, A., Salzillo, R., Catalano, C., D’Agostino, A., Pirozzi, A. V. A., De Rosa, M. \& Schiraldi, C. (2019). Hyaluronan-based hydrogels as dermal fillers: The biophysical properties that translate into a "volumetric" effect. PLoS One, 14(6). 
La Gatta, A., Schiraldi, C., Zaccaria, G. \& Cassuto, D. (2020). Hyaluronan Dermal Fillers: Efforts Towards a Wider Biophysical Characterization and the Correlation of the Biophysical Parameters to the Clinical Outcome. Clin Cosmet Investig Dermatol., 13, 87-97.

Lee, W., Hwang, S-G., Oh, W., Kim, C-Y., Lee, J-L. \& Yang, E-J. (2020). Practical Guidelines for Hyaluronic Acid Soft-Tissue Filler Use in Facial Rejuvenation. Dermatol Surg., 46(1), 41-49.

Lipko-Godlewska, S., Bolanča, Ž., Kalinová, L., Kermen, I., Onisak, B., Papp, I., Rebrov, M. \& Valančienė, G. (2021). Whole-Face Approach with Hyaluronic Acid Fillers. Clin Cosmet Investig Dermatol., 14, 169-178.

Maia, I. E. F. \& Salvi, J. de O. (2018). O Uso do Ácido Hialurônico na Harmonização Facial: Uma Breve Revisão. Brazilian Journal of Surgery and Clinical Research, 23(2), 135-139.

Maytin, E. V. (2016). Hyaluronan: More than just a wrinkle filler. Glycobiology, 26 (6), 553-559.

McKeown, D. J. (2021). Impact of Minimally Invasive Aesthetic Procedures on the Psychological and Social Dimensions of Health. Plast Reconstr Surg Glob Open., 9(4), 3578.

Michaud, T. (2016). Rheology of hyaluronic acid and dynamic facial rejuvenation: Topographical specificities. J Cosmet Dermatol., 17(5), 736-743.

Nakab, L., Hee, C. K. \& Guetta, O. (2020). Improvements in Skin Quality Biological Markers in Skin Explants Using Hyaluronic Acid Filler VYC-12L. Plast Reconstr Surg Glob Open., 8(3), 2723.

Niforos, F., Acquilla, R., Ogilvie, P., Safa, M., Signorini, M., Creutz, L., Kerson. G. \& Silberberg, M. (2017). A Prospective, Open-Label Study of Hyaluronic Acid-Based Filler With Lidocaine (VYC-15L) Treatment for the Correction of Infraorbital Skin Depressions. Dermatol Surg., 43(10), 1271-1280.

Ogilvie, P., Benouaiche, L., Philipp-Dormston, W. G., Belhaouari, L., Gaymans, F., Sattler, G., Harvey, C \& Schumacher, A. (2020). VYC-25L Hyaluronic Acid Injectable Gel Is Safe and Effective for Long-Term Restoration and Creation of Volume of the Lower Face. Aesthet Surg J., 40(9), 499-510.

Rohrich, R. J., Bartlett, E. L. \& Dayan, E. (2019). Practical Approach and Safety of Hyaluronic Acid Fillers. Plast Reconstr Surg Glob Open., 7(6), 2172.

Rzany, B., Bayerl, C., Bodokh, I., Boineau, D., Dirschka, T., Queille-Roussel, C., Sebastian, M., Sommer, B. Edwartz, C. \& Podda, M. (2017). An 18-Month Follow-up, Randomized Comparison of Effectiveness and Safety of Two Hyaluronic Acid Fillers for Treatment of Moderate Nasolabial Folds. Dermatol Surg., 43(1), 58-65.

Shin, J-W., Kwon, S-H., Choi, J-Y., Na, J-I., Huh, C-H., Choi, H-R \& Park, K-C. (2019). Molecular Mechanisms of Dermal Aging and Antiaging Approaches. Int J Mol Sci., 20(9), 2126.

Singh, K. \& Nooreyezdan, S. (2020). Nonvascular Complications of Injectable Fillers-Prevention and Management. Indian J Plast Surg., 53(3), $335-343$.

Sito, G., Manzoni, V. \& Sommariva, R. (2019). Vascular Complications after Facial Filler Injection: A Literature Review and Meta-analysis. J Clin Aesthet Dermatol., 12(6), 65-72.

Stojanovič, L. \& Majdič, N. (2019). Effectiveness and safety of hyaluronic acid fillers used to enhance overall lip fullness: A systematic review of clinical studies. J Cosmet Dermatol., 18(2), 436-443.

Vandeputte, J. (2018). Real-world Experience with Volume Augmentation using Cohesive Polydensified Matrix Hyaluronic Acid Gel: A Retrospective Singlecenter Analysis of 110 Consecutive Patients with Medium- to Long-term Follow-up. J Clin Aesthet Dermatol., 11(12), 30-39.

Vasconcelos, S. C. B., Nascente, F. M., De Souza, C. M. D. \& Sobrinho, H. M. da R. (2020). O uso do ácido hialurônico no rejuvenescimento facial. Revista Brasileira Militar De Ciências, 6(14), 8-15.

Wang, C., Luan, S., Panayi, A. C., Xin, M., Mi, B. \& Luan, J. (2018). Effectiveness and Safety of Hyaluronic Acid Gel with Lidocaine for the Treatment of Nasolabial Folds: A Systematic Review and Meta-analysis. Aesthetic Plast Surg., 42(4), 1104-1110.

Wollina U \& Goldman A. (2020). Facial vascular danger zones for filler injections. Dermatol Ther., 33(6), 14285.

Wu, Y., Sun, N., Xu, Y., Liu, H., Zhong, S., Chen, L. \& Li, D. (2016). Clinical comparison between two hyaluronic acid-derived fillers in the treatment of nasolabial folds in Chinese subjects: BioHyalux versus Restylane. Arch Dermatol Res., 308(3), 145-151. 